\title{
Automation of the Requisition Process in Material Supply Chain of Construction Firms
}

\author{
Adedeji Afolabi, Yewande Abraham, Rapheal Ojelabi, \\ and Oluwafikunmi Awosika
}

\begin{abstract}
Construction materials play a crucial role in the project delivery process. However, the process of requisition for the materials on construction site if not handled appropriately can adversely affect the performance of quality, cost, and time. Therefore, the study was aimed at developing an automated materials requisition system which will make the supply chain on construction sites seamless and more effective. A use case diagram and an activity block diagram helped to understand the users and functionalities of the material requisition platform. In addition, using different user interface and a database system including a programming language to connect them, the study developed an automated Web-based material requisition system for construction firms using the model view controller (MVC) model. The MVC model comprised of using MySQL, HTML, and PHP, respectively, in the design. The automated materials requisition system was tested by sending material requisition through the supply chain of a construction firm. Result of the automated system was presented via screenshots of the Web-based platform. In conclusion, any construction firm can register on the platform and make use of the automated materials requisition system in order to maximize the productivity and optimize the use of ICT in their materials' supply chain process.
\end{abstract}

Keywords Automation $\cdot$ Construction industry $\cdot$ Materials $\cdot$ Requisition $\cdot$ Supply chain

\footnotetext{
A. Afolabi $(\varangle) \cdot$ R. Ojelabi · O. Awosika

Covenant University, Ota, Nigeria

e-mail: adedeji.afolabi@ covenantuniversity.edu.ng

Y. Abraham

Rochester Institute of Technology, Rochester, NY, USA
} 